\title{
Knowledge, Attitude, and Perception on Bequeathing of Bodies for Medical Education and Research among Health Science Students of the University of Health and Allied Sciences.
}

Henrietta Enam Quarshie

University of Health and Allied Sciences

Raymond Saa-Eru Maalman ( $\Delta$ rmaalman@uhas.edu.gh )

University of Health and Allied Sciences

Mahamudu Ayamba Ali

University of Health and Allied Sciences

Yaw Otchere Donkor

University of Health and Allied Sciences

Kingsley Ampong

University of Health and Allied Sciences

Jerry Quaye

University of Health and Allied Sciences

Rufai Safianu

University of Health and Allied Sciences

Isaac Ekow Ennin

University of Health and Allied Sciences

Joseph K. Korpisah

University of Health and Allied Sciences

\section{Research Article}

Keywords: Body Bequeathal, Medical Science Education, Cadaveric Dissection, Anatomical education

Posted Date: January 12th, 2022

DOI: https://doi.org/10.21203/rs.3.rs-1232943/v1

License: () (1) This work is licensed under a Creative Commons Attribution 4.0 International License.

Read Full License 


\section{Abstract}

Abstract Background: Cadaveric dissection is an established effective teaching method in anatomical science education. Cadaver acquisition for dissection is however based on voluntary body bequeathment. As a result of the increasing numbers of medical schools and students intake, the challenges of inadequate bodies for education became visible in most parts of the world as the main cadaver source remains anonymous corpses in the custody of the state. Cultural and religious beliefs or commercial purposes are among several factors that influence the decision about body donations. This study investigates the knowledge, attitude and perception of body bequeathing among health science students who benefitted or are potential beneficiary of cadaveric studies and identified factors influencing the bequest of bodies in Ghana for educational purposes among students in University of Health and Allied Sciences. Method: This was a cross-sectional descriptive study. The study recruited 513 students in the bachelor programmes for medicine, physician assistantship, nursing, midwifery, pharmacy and allied sciences at various levels. Both closed-and open-ended questions contained in a designed Questionnaire were administered. Result: About Seventy-four percent (74.1\%) of respondents had heard of body bequeathal. Majority (98.3\%) agreed body bequeathal was important. However, only $39.6 \%$ knew the requirements and processes of body bequeathal. Most ( $>90 \%)$ had a negative attitude towards body bequeathal. Conclusion: The study concluded that there was a high awareness of the importance of body bequeathal for medical education and research but very low procedural knowledge on bequeathing a body among health science students. Also most were unwillingness to donate their body or even encouraging others to donate their body. It is therefore recommended that the medical schools should set up accessible body bequeathal programmes that provides opportunities for interested individuals to be readily assisted through the process of body bequeathal. Keywords: Body Bequeathal, Medical Science Education, Cadaveric Dissection, Anatomical education

\section{Background}

Anatomical science is studied in almost all health professional training programmes including Medicine, Dentistry, Nursing and Pharmacy[1]. A better understanding of the subject is relevant in eliciting clinical signs, providing clinical reasoning for diagnosis and effective invasive procedures or intervention in surgical pathologies [2]. Firm knowledge of structural forms is required in the design of surgical instruments and the acquisition of tactile sense. Cadaveric dissection is an integral component of medical education $[3,4]$. in the acquisition of firm knowledge in anatomy. Even though the advent of modern technology has allowed availability and access to simple, clean and hazard free representations of the human body such as 3D prints and virtual simulations like anatomage machine, these are sophisticated and expensive especially in the developing countries and does not provide the dissection skill or tactile sense development. Cadaveric dissection remains an effective teaching and learning method for undergraduate and postgraduate anatomy programmes. Thus, most academicians, students and clinicians have attested that gross anatomy is better understood through body dissection which must be sustained through whole body bequeathal [3-5] to medical schools. Body bequeathal 
programmes are usually governed by an act, and in Ghana, the Anatomy Act 280, 1965 regulates its process [6].

The problem of body acquisition for cadaveric dissection remains a challenge to many medical schools, especially in Ghana which has increasing numbers of medical schools and students intake. The traditional cadaveric source which has been largely unclaimed bodies is no longer reliable and does not satisfy the increasing needs for it [7-10].

Several factors might influence the decision to be a body donor. These factors may include the awareness of the programme, cultural, religious beliefs, love for humanity, medical research and education [11]. This study, therefore, investigates the knowledge, attitude and perception of body bequeathing for medical science education among human health science students at the University of Health and Allied Sciences (UHAS). The study specifically assessed students' knowledge on the bequest of bodies; explored students' perception of body donation; their attitude towards the bequeathing of bodies and identified factors influencing the bequeathal of bodies in Ghana for basic medical science education and research.

\section{Materials And Methods}

Study design and participants' recruitment criteria: This was a cross-sectional descriptive study. It involved participants whose academic curriculum required practical anatomy lessons with cadavers either in the form of dissection or use of prosected bodies for demonstration. Thus, the schools include Medicine, Nursing and Midwifery, Allied Health Sciences and Pharmacy. They were studying the Bachelor programmes, preclinical or clinical levels. Students who desired not to participate were excluded from the study.

Sample size determination: A sample size of 385 participants was determined based on Yamane's formula with a $10 \%$ non-respondent rate. Non-probability sampling was used in the study. However, a total of 513 responded to a structured questionnaire and that has been used for analysis.

Data collection tool and procedure: The students were anonymously identified based on the various listed schools' registers with the contacts of email addresses. A questionnaire on an online google form link was sent through the university email addresses to the study participants for responses at their convenience. The questionnaire had sections that collected data on their knowledge, attitude and perception of body bequeathal for basic medical science education and also factors that influenced the personal decision to participate in body bequeathal programmes or recommend the practice. There were items with close-ended and open-ended questions. 
Statistical analysis: Data were downloaded and organized in Microsoft Excel ${ }^{\circledR}$ spreadsheets and an analysis software Stata 16.0 was used for the analysis. Data were analysed using descriptive and inferential statistics and results were presented in tabular form. P-value of $<0.05$ was considered to have statistical significance parametric or non-parametric data.

\section{Ethical issues}

The proposal for the study was submitted to the UHAS Research Ethical Committee for ethical clearance and it was approved with the assigned number; UHAS-REC A.12[95]20-21. The consent of the Head of the Anatomy Department was sought. The anonymity of participants was ensured by using codes for individual answered questionnaires received. Participation in the study was voluntary and respondents could withdraw at any stage of the data collection process.

\section{Results}

\section{Demographic characteristics}

Table 1 shows that the majority of the respondents 406 (79.1\%) were between the ages of 17-25 years (24.0 \pm 4.8 years). Female constituted $273(53.2 \%)$ and 236 (46\%) of respondents were from the School of Medicine. Fourth and final year medical students were respectively $132(25.7 \%)$ and $37(7.2 \%)$. The majority 488 (95.1\%) were Christians

\section{Table 1: Demographic characteristics of respondents $(n=513)$}




\begin{tabular}{|c|c|c|}
\hline Variable & Frequency (No.) & Percent (\%) \\
\hline \multicolumn{3}{|l|}{ Age* of the respondent $^{*}$} \\
\hline $17-25$ & 406 & 79.1 \\
\hline $26-35$ & 90 & 17.5 \\
\hline $36-43$ & 17 & 3.3 \\
\hline \multicolumn{3}{|l|}{ Sex } \\
\hline Female & 273 & 53.2 \\
\hline Male & 240 & 46.8 \\
\hline \multicolumn{3}{|l|}{ School } \\
\hline Medicine & 236 & 46.0 \\
\hline Nursing and Midwifery & 144 & 28.0 \\
\hline Allied Health & 109 & 21.2 \\
\hline Pharmacy & 24 & 4.7 \\
\hline \multicolumn{3}{|l|}{ Year of study } \\
\hline $100\left(1^{\text {st }}\right)$ & 115 & 22.4 \\
\hline $200\left(2^{\text {nd }}\right)$ & 74 & 14.4 \\
\hline $300\left(3^{\text {rd }}\right)$ & 111 & 21.6 \\
\hline $400\left(4^{\text {th }}\right)$ & 132 & 25.7 \\
\hline $500\left(5^{\text {th }}\right)$ & 44 & 8.6 \\
\hline $600\left(6^{\text {th }}\right)$ & 37 & 7.2 \\
\hline \multicolumn{3}{|l|}{ The religion of the respondent } \\
\hline Christian & 488 & 95.1 \\
\hline Muslim & 25 & 4.9 \\
\hline
\end{tabular}

*Mean age $=24$ years; range 17-43 years with a standard deviation $=4.8$

Knowledge of students on bequeathing of bodies for medical science education

Table 2 summarizes the general knowledge of the respondents on body bequeathal, majority $380(74.1 \%)$ have heard of it with $47.9 \%$ aware of the requirement to complete legal documentation while $45.6 \%$ thought making one's family aware was a requirement. However, $214(41.7 \%)$ did not know what was required in the process of body bequeathal and 5 responses representing $1 \%$ reported that nothing was required. On the use of bequeathed bodies, a majority (89.3\%) identified teaching and learning of anatomy and $78.8 \%$ indicated that medical research was a possible use.

\section{Table 2: Knowledge of Body Bequeathal}




\begin{tabular}{lrrr}
\hline ariables & $\begin{array}{r}\text { Freq } \\
\text { (No.) }\end{array}$ & $\begin{array}{r}\text { Percent } \\
\text { (\%) }\end{array}$ & $\begin{array}{r}\text { Knowledge level } \\
\text { (\%) }\end{array}$ \\
leard of body bequeathal in Ghana & 380 & 74.1 & 74.1 \\
$\quad$ Yes & 133 & 25.9 & \\
No & 5 & 0.9 & \\
he requirement for body bequeathal & 165 & 32.2 \\
Nothing is required & 234 & 45.6 \\
Copy of a death certificate & 114 & 22.2 \\
Making one's family aware & 110 & 21.4 & \\
Body disposal permit by the & 10 & 1.9 \\
government & 144 & 28.1 & \\
Body not too thin/not too fat & 246 & 47.9 & \\
Body without disease & 214 & 41.7 & \\
Body not under police investigation & & & \\
Filling legal forms & & 78.6 \\
No idea & 404 & 75.8 & \\
se of bequeathed bodies & 233 & 45.4 & \\
Medical research & 458 & 89.3 & \\
Medical testing & 40 & 7.8 & \\
Anatomy teaching and learning & &
\end{tabular}

Respondents attitude towards body bequeathal

Table 3 summarises the attitude of the study respondents towards the body bequeathal and the association with their demographic characteristics. Only a few $(9.8 \%)$ of the respondents expressed their willingness to bequeath their bodies for anatomical education and research while $43.9 \%$ were undecided about bequeathing their bodies. On donation of organs, $24.8 \%$ are willing to donate their organs to others for medical purposes to save their lives. Medical education and research had response rates of $83.2 \%$ and $86.2 \%$ respectively. Body bequeathal is also helpful in making one contribute to society $(30.4 \%)$.

On whom respondents will encourage to bequest body, $45.0 \%$ of the responses showed that respondents were indecisive on who they were willing to encourage to bequest while $29.4 \%$ said they will encourage anyone to bequest. On how their cultural backgrounds are related to body bequeathal, most 381 (74.3\%) of the respondents reported that their culture supported body bequeathal. Meanwhile $370(72.2 \%)$ of the respondents did not however know what their religion had to say about body bequeathal.

\section{Table 3: Respondents' attitude towards the bequeathing of bodies}




\begin{tabular}{lrr}
\hline Variables & Freq (No.) & Percent (\%) \\
\hline Willingness to bequeath body & 50 & 9.8 \\
Yes & 238 & 46.4 \\
No & 225 & 43.9 \\
Undecided & 127 & 24.8 \\
Willing to donate any organs & 170 & 33.1 \\
Yes & 216 & 42.1 \\
No & & \\
Undecided & 427 & 83.2 \\
The usefulness of body bequeathal & 442 & 86.2 \\
Medical research & 156 & 30.4 \\
Medical education & 7 & 1.4 \\
Making one contribute to the good of society & 37 & 7.2 \\
Making one popular & & 32.6 \\
I don't know & 51 & 9.9 \\
Person one will encourage to bequeath their bodies & 54 & 10.8 \\
Family & 147 & 29.4 \\
Friends & 51 & 9.9 \\
Anyone & 100 & 20.0 \\
Myself & 225 & 45.0 \\
No one & & \\
Undecided & 381 & 74.3 \\
Culture's relation to organ/body bequeathal & 86 & 16.2 \\
My culture supports it & 32 & 6.2 \\
My culture is against it & 17 & 3.3 \\
It is not part of my culture & & \\
I don't know what my culture says about it & 44 & 8.6 \\
Religion's relation to organ/body bequeathal & 23 & 4.5 \\
My religion supports it & 370 & 72.8 \\
My religion is against it & & \\
It is not part of my religion & & \\
I don't know what my religion says about it & & \\
\hline
\end{tabular}

Perception of students on body bequeathing in medical science education and research

Table 4 shows the perception of respondents on body bequeathal where $35.7 \%$ of respondents were indecisive about what they feared when they thought about body bequeathal while fear of misuse of the body had a response rate of $24.8 \%$. Notably, a majority $217(42.3 \%)$ of the respondents would prefer to bequest their bodies to their families. The majority $46.0 \%$ viewed bequest as a family decision meanwhile, 242 ( 47.2\%) were indecisive.

Table 4: Perception of students on body bequeathing for medical science education and research 


\begin{tabular}{lrr}
\hline Variables & $\begin{array}{r}\text { Freq } \\
\text { (No.) }\end{array}$ & $\begin{array}{c}\text { Percent } \\
\text { (\%) }\end{array}$ \\
\hline What are your fears about body bequeathal & 152 & 29.6 \\
I'm not afraid & 79 & 15.4 \\
Disrespect & 87 & 16.9 \\
Sale of my body part & 127 & $24 . .8$ \\
Misuse of my body & 183 & 35.7 \\
Undecided & 9 & 1.8 \\
Others & & \\
Persons who will NOT support the decision to bequest one's & 236 & 46.0 \\
body & 72 & 14.0 \\
Family & 48 & 9.4 \\
Friends & 63 & 12.3 \\
My religion & 242 & 47.2 \\
My culture & 9 & 1.8 \\
Undecided & 217 & 42.3 \\
Other & 89 & 17.4 \\
Who one prefers to bequest organ/body to & 126 & 24.6 \\
Family & 76 & 14.8 \\
Friends & 151 & 29.4 \\
Any medical/research institution & 2 & 0.4 \\
No one & & \\
Undecided & & \\
Other & & \\
& &
\end{tabular}

Further analysis using a Pearson's $\chi^{2}$ test of independence test shows no association between age, sex, programme, level of study, religion and attitude toward body bequeathal P-value $>0.05$ ).

Factors that influence body donation

Respondents reported multiple factors that will inspire them to bequest their bodies. To further obtain more information on the factors that influence body bequest, respondents were asked open-ended questions; to state the MOST important factors that will influence their decision to bequest their bodies. Upon analysis, three main themes emerged from the responses as follows:

1. Approval from family, culture and religion

2. Mishandling of bequeathed body

3. The desire to be useful after death

\section{Theme 1: Approval by family, culture and religion}

One of the key themes that emerged from the respondents was that their decision to partake in body bequeathal will depend on whether or not their families, culture or religion approved it. Many of the responses that were stated revealed that respondents think that what their families had to say concerning 
body bequeathal will determine if they will bequest their bodies. Some of the respondents' statements are quoted as follows:

"I will consider my family's opinion on the matter; When my nuclear family decides or disagrees; Refusal from spouse/children/family; My family is uncomfortable, Family consent; If there is a strong resistance from my family".

Some also stated that they will consider what their religion or faith and culture say concerning body bequeathal and will consider bequeathing if only these are in approval and are stated as follows;

"My customs and traditions; When my religion stands against it; The fact that my parents or religion will disagree; Religious disapproval; My faith".

Importantly, it was noted that most respondents will also be prevented from bequeathal by disapproval from both their culture and religion as in the following statements.

"If it is against my cultural or religious belief; Disrespect to my body; culture, and religion".

\section{Theme 2: Mishandling of bequeathing body by the students and staff}

There was concern amongst the respondents about how their bequeathed bodies will be handled. Respondents reported that they were concerned about their privacy and whether or not their bequeathed bodies will be treated with respect while being used. Some reported that they feared their bequeathed bodies would be sold for other purposes. Hence most of them will consider whether or not their bequeathed bodies will be used for the purpose for which they agree to bequest. The following were reported;

"My dignity and respect; privacy during usage; Disrespect and derogatory remarks; My sentiments about misuse and disrespect for body parts; Selling my body parts; mistrust of doctors; hospitals, and the organ allocation system; and a belief in a black market for rituals; What If my body is not kept well; I've seen how bodies are handled in my school's anatomy lab some get infected with fungi".

\section{Theme 3: The desire to be useful after death}

Another factor that stood out was the desire to be useful after death. Some of the respondents stated their willingness to bequest their bodies to aid in the advancement of medical science and research. Notably, some will consider the option of organ donation if not whole body bequeathal to save the lives of others who might need these organs for transplants. They recounted that if the bequeathal of their bodies will aid in medical research, science and education of medics, it will mean they are being useful even after death. Some also reported that it will be for the good of society and the health of those to 
whom their organs will keep alive. They are as follows: "Usefulness to medicine; The benefits it will serve to the society through learning anatomy and research; Saving lives; The health and wellbeing of the one receiving my organ; No waste of resources on the dead body which can be useful in helping others; and The benefit it will be to the society" were the factors that will inspire them to donate their bodies.

\section{Discussion}

\section{Knowledge of students on bequeathing of bodies for medical science education}

The present study reveals that most (74.1\%) of the respondents had heard about body donation and almost all of them (98.3\%) knew the importance of bequeathed bodies for the teaching and learning of anatomy in medical education. This might be due to the respondents being students in health training universities. Furthermore, most of the students particularly the medical and physiotherapy students had had cadaveric dissections for the teaching and learning of anatomy and might have been informed by their instructors. Similarly, a previous study by Ciliberti et al.[12] among Italian medical students also reported high awareness of body bequeathal as cadaver dissection was an important part of their education. Contrary to this finding among students, previous studies $[11,13-15]$ amongst the general population reported poor knowledge of body bequeathal. This is likely because of a lack of prior exposure to the use of bequeathed bodies in anatomical education and research in the general population.

In a previous study amongst Italian medical students by Ciliberti et al.[12] (2018), students were not aware of the processes involved in body bequest. This was attributed to a general lack of awareness of programmes amongst these students from that study. This current study also corroborated this finding of a low level of knowledge of the requirement of body bequeathal.

Despite the knowledge on the importance of bequeathed bodies for the teaching and learning of anatomy in medical education, respondents in this study had very low knowledge (39.6\%) on the requirements for body bequeathal. Respondents in this study mentioned the requirement for body bequeathal to include filling legal forms (48\%), a copy of a death certificate (32.2\%), making one's family aware $234(45.6 \%)$, and body not under police investigation $144(28.1 \%)$. This result is likely due to students not being actively involved in the process of acquisition of bodies that they use for their anatomy education.

\section{The attitude of students towards bequeathing of bodies for medical science education}

The current study reveals that the willingness to bequest their bodies for anatomical education and research was very low (9.8\%). This finding confirms a study by Abbasi et al.[13] among Iranian students. In the present study, although respondents recognized how beneficial bodies bequeathed were to medical education, they exhibited a poor attitude toward it. This poor attitude was further exhibited, as only $32.6 \%$ were willing to encourage other people to participate in body bequeathal which is similar to findings by Alexander et al.[16]. This study reveals that $24.8 \%$ of respondents were willing to bequest part 
of their bodies such as organs as opposed to $9.8 \%$ willingness for whole body bequeathal. This indicates that respondents have a higher likelihood of donating their organs than the whole body. Previous studies $[17,18]$ reported similar findings. A possible explanation for this finding might be the desire of respondents to be useful in saving lives through organ bequest for medical transplants.

In the present study, even though, most of the respondents were not certain on the dictates of their religion or their culture, they admitted that they will only be willing to partake in body bequeathal if it was permitted by their religion and culture. Rokade and Bahetee [17] also observed in their study that most people were unaware of the views of their various religions on body bequest. Thus, the attitude of respondents towards body bequeathal whether positive or negative was hence determined by personal thoughts and intuitions with regards to their religious and cultural beliefs.

Other previous studies corroborate the present study where they reported that people who were willing to bequest their bodies did so for altruistic reasons [19]. Thus, most of the bodies are bequeathed by people who were willing to bequest due to their beliefs in unselfish regard or devotion to the human race hence; altruism [19]. As was demonstrated in the current study, very few; $1.4 \%$ reported that body bequeathal will serve the personal purpose of making themselves popular.

\section{Perception of students on bequeathing of bodies for medical science education}

Some of the respondents in this study reported that they feared their bodies will be misused, 127 (24.8\%) or that their body parts will be sold, 87 (16.9\%). These thoughts could prevent body bequeathal. These findings were in line with similar studies where respondents stated that they were unwilling to bequest their bodies due to similar fears of misuse and sale of body parts [17, 20,21].

The current study showed that 236 (46.0\%) reported that their families will not support their decision to bequest their bodies just as Mwachaka et al. [22] reported in a study where respondents said their decision will be deterred by their families. Some considered that there will be a loss of family ties after their death if they bequest their bodies. The present study offers a clearer understanding of why respondents were unwilling to bequest their bodies if their families did not approve of their decision to bequest. In this study, respondents also showed concern of unacceptability of body bequeathal by their families and this was a similar finding to a previous study by Sehirli et al.[23]

Furthermore, respondents in this study portrayed a general sense of uneasiness about how their bodies might be handled specially during anatomy dissection. As was seen even amongst groups of people who are willing to or have joined bequeathal programmes, there is still the mindset that there will be a lack of respect or due dignity to their bodies in the laboratory [11]. This therefore could be an important factor that will prevent bequeathal even though the importance of bequeathed bodies in medical education and research is well known amongst the respondents.

Page 11/15 
In this study very few of the respondents, $24.8 \%$ will consider organ donation and this was still a higher number in comparison to those who were willing to participate in whole body bequeathal, $9.8 \%$. This was as reported in studies by Rokade and Bahetee [17] and Arráez-Aybar et al.[18].

\section{Factors that influence body bequeathal}

Previous studies indicated that a common reason for making a body bequest is to aid medical science education and research $[20,21,22,25]$. This was evident in this study, as the respondents reported that contributing to advancement in medical research and anatomy are factors that will inspire them to bequest their bodies; 284 (55.3\%). The current study reveals that $23.8 \%$ of the respondents believed that being useful after death was more inspiring to participate in body bequeathal programmes. For $30.4 \%$ of the respondents, they will bequest to contribute to the good of society. These findings are in line with observations from a previous study by Ajita and Singh [19].

The respondents in this study reported that the love of family $149(29 \%)$ and love of friends $78(15.2 \%)$ as factors that will inspire them to participate in body bequeathal. The anxiety of disrespectful behaviour to cadavers as seen by Sehirli et al.[23] was also reported by respondents in this study as a factor that will prevent them from body bequeathal. As was reported via answers from open-ended questions in this study; most of the respondents reported that they feared that their bequeathed bodies will be treated with disrespect.

In this current study, themes from open-ended questions also revealed that approval of others; family, culture and religion, fear of mishandling of bequeathed bodies and the desire to be useful after death were important factors that will influence the decision to either bequeath or not. This was not a different observation from various studies that had been conducted [17, 20, 21]. Unlike in previous studies [26, 27], this current study did not show any significant influence of sex or age on body bequeathal. The context of this study should however be taken into consideration as the age group of the respondents (17-43 years ) in this current study is not as varied as in previous studies.

\section{Conclusion}

This study concludes that there is a high awareness of the importance of body bequeathal for basic medical science education and research. There was however very low knowledge with regards to the processes required for a person to bequest their body. The study reveals a negative attitude of respondents towards the willingness to donate their body or even recommending others to donate their body. Notable factors that might influence body bequeathal were disapproval of families, religion or culture, protection of privacy and fear of mishandling and misuse of their bequeathed bodies. There was no influence of age or sex on the decision to bequest among respondents. It is therefore recommended that the medical schools should set up accessible body bequeathal programmes which will provide opportunities for interested individuals to be readily assisted through the process of body bequeathal. 


\section{Declarations}

\section{Consent for publication}

Not applicable

\section{Availability of data and Materials}

The datasets used during the current study are available from the first and corresponding authors on reasonable request.

\section{Competing interest}

The authors declare that they have no competing interests.

\section{Funding}

There was no funding received for this project.

\section{Author's contributions}

HEQ and RSM made contributions to the conception and design of the study. MAA, OYD and KA made a substantial contribution to the study design and management of the research activities. HEQ and RSM analysed the data and drafted the manuscript. All authors were involved in critical revision for important intellectual content and approved the final manuscript.

\section{Acknowledgement}

We would like to acknowledge the students of the University of Health and Allied Sciences (UHAS) who played various roles in the project.

\section{References}

1. Biswas R, Bandyopadhyay R. Attitude of first-year medical students towards cadaveric dissection: a cross-sectional study in a medical college of West Bengal, India. Int J Community Med Public Health [Internet]. 2019 Jun:2679-83.

2. Dissabandara LO, Nirthanan SN, Khoo TK, Tedman R. Role of cadaveric dissections in modern medical curricula: a study on student perceptions. Anatomy \& cell biology. 2015 Sep 1;48(3):205-12.

3. Asante EA, Maalman RS, Ali MA, Donkor YO, Korpisah JK. Perception and Attitude of Medical Students towards Cadaveric Dissection in Anatomical Science Education. Ethiopian Journal of Health Sciences. 2021 Jul 1;31(4).

4. Saw A. A new approach to body donation for medical education: The silent mentor programme. Malaysian orthopaedic journal. $2018 \mathrm{Jul} ; 12(2): 68$. 
5. Saha A, Sarkar A, Mandal S. Body donation after death: The mental setup of educated people. Journal of clinical and diagnostic research: JCDR. 2015 Jun;9(6):AC05.

6. Constitution of the Republic of Ghana. Ghana Publishing Corporation (Print. Division); 1992.

7. Gangata $\mathrm{H}$, Ntaba P, Akol P, Louw $G$. The reliance on unclaimed cadavers for anatomical teaching by medical schools in Africa. Anatomical sciences education. 2010 Jul;3(4):174-83.

8. Akinola OB. Formal body bequest program in Nigerian medical schools: When do we start?. Anatomical sciences education. $2011 \mathrm{Jul} ; 4(4): 239-42$.

9. EwonuBari EB, Watson JT, Amaza DS, Madueke NM, Donatus AA, Effiong OE. Problems and prospects of acquisition of human cadaver for medical education in Nigeria. J Pak Med Assoc. 2012 Nov 1;62(11):1134-6.

10. Cornwall J, Perry GF, Louw G, Stringer MD. Who donates their body to science? An international, multicenter, prospective study. Anatomical sciences education. 2012 Jul;5(4):208-16.

11. Richardson R, Hurwitz B. Donors' attitudes towards body donation for dissection. The Lancet. 1995 Jul 29;346(8970):277-9.

12. Ciliberti R, Gulino M, Gazzaniga V, Gallo F, Vellone VG, De Stefano F, Santi P, Baldelli I. A survey on the knowledge and attitudes of Italian medical students toward body donation: ethical and scientific considerations. Journal of clinical medicine. 2018 Jul;7(7):168.

13. Abbasi AsI J, Nikzad H, Taherian A, Atlasi MA, Naderian H, Mousavi G, Kashani MM, Omidi A. Cultural acceptability and personal willingness of Iranian students toward cadaveric donation. Anatomical sciences education. 2017 Mar;10(2):120-6.

14. Boulware LE, Ratner LE, Cooper LA, LaVeist TA, Powe NR. Whole-body donation for medical science: A population-based study. Clinical Anatomy: The Official Journal of the American Association of Clinical Anatomists and the British Association of Clinical Anatomists. 2004;17(7):570-7.

15. Marqués-Lespier JM, Ortiz-Vega NM, Sánchez MC, Soto-Avilés OE, Torres EA. Knowledge of and attitudes toward organ donation: A survey of medical students in Puerto Rico. Puerto Rico health sciences journal. 2013 Nov 21;32(4).

16. Alexander M, Marten M, Stewart E, Serafin S, Štrkalj G. Attitudes of Australian chiropractic students toward whole body donation: A cross-sectional study. Anatomical sciences education. 2014 Mar;7(2):117-23.

17. Rokade, S. A., \& Bahetee, B. H. Body donation in India: a review. International Journal of Research in Medical Sciences, 1(3), (2017)173-177. https://www.msjonline.org/index.php/ijrms/article/view/2583

18. Arráez-Aybar LA, Castaño-Collado G, Casado-Morales MI. Dissection from the Spanish anatomist's perspective: Aims, attitudes, and related aspects. The Anatomical Record Part B: The New Anatomist: An Official Publication of the American Association of Anatomists. 2004 Nov;281(1):15-20.

19. Ajita R, Singh Y.I. (2007). Body donation and its relevance in anatomy learning- a review. JASI 56(1):44 
20. Alashek WA, Ehtuish EF, Elhabashi A, Emberish W, Mishra A. Reasons for unwillingness of Libyans to donate organs after death. Libyan Journal of Medicine. 2009;4(3).

21. Bolt S, Venbrux E, Eisinga R, Kuks JB, Veening JG, Gerrits PO. Motivation for body donation to science: More than an altruistic act. Annals of Anatomy-Anatomischer Anzeiger. $2010 \mathrm{Apr}$ 20;192(2):70-4.

22. Mwachaka PM, Mandela P, Saidi H. Repeated exposure to dissection does not influence students' attitudes towards human body donation for anatomy teaching. Anatomy research international. 2016;2016.

23. Şehïrli ÜS, Saka E, Sarikaya Ö. Attitudes of Turkish anatomists toward cadaver donation. Clinical Anatomy: The Official Journal of the American Association of Clinical Anatomists and the British Association of Clinical Anatomists. 2004;17(8):677-81.

24. McClea K, Stringer MD. The profile of body donors at the Otago School of Medical Sciences-Has it changed. NZ Med J. 2010 Apr 9;123(1312):9-17.

25. Ballala K, Shetty A, Malpe SB. Knowledge, attitude, and practices regarding whole body donation among medical professionals in a hospital in India. Anatomical sciences education. 2011 May;4(3):142-50.

26. Fennell S, Jones DG. The bequest of human bodies for dissection: a case study in the Otago Medical School. The New Zealand medical journal. 1992 Nov 1;105(946):472-4.

27. Dluzen DE, Brammer CM, Bernard JC, Keyser ML. Survey of cadaveric donors to a body donation program: 1978-1993. Clinical Anatomy. 1996;9(3):183-92. 